\title{
THE VERTICAL LAND MOTION OF TIDE GAUGE AND ABSOLUTE SEA LEVEL RISE IN BOHAI SEA
}

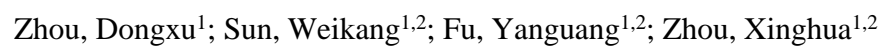 \\ ${ }^{1}$ The First Institute of Oceanography, Ministry of Natural Resources, People's Republic of China;-( zhoudongxu, sunweikang, ygfu, \\ xhzhou)@ fio.org.cn \\ ${ }^{2}$ Shandong University of Science and Technology, People's Republic of China
}

KEY WORDS: Co-located GNSS stations, Tide Gauges, Vertical Land Motion, Absolute Mean Sea Level Change, Relative Mean Sea Level Change

\begin{abstract}
The ground vertical movement of the tide gauges around the Bohai sea was firstly analyzed by using the observation data from 2009 to 2017 of the nine co-located GNSS stations. It was found that the change rate of ground vertical motion of four stations was in the same order of magnitude as the sea level change. In particular, the land subsidence rate of BTGU station reaches $11.47 \mathrm{~mm} / \mathrm{yr}$, which should be paid special attention to in the analysis of sea level change. Then combined with long-term tide gauges and the satellite altimetry results, the sea level changes in the Bohai sea and adjacent waters from 1993 to 2012 were analyzed. The relative and absolute sea level rise rates of the sea area are $3.81 \mathrm{~mm} / \mathrm{yr}$ and $3.61 \mathrm{~mm} / \mathrm{yr}$, respectively, both are higher than the global average rate of change. At the same time, it is found that the vertical land motion of tide gauge stations is the main factor causing regional differences in relative sea level changes.
\end{abstract}

\section{INTRODUCTION}

In the Fifth Assessment Report of the Intergovernmental Panel on Climate Change (IPCC) in 2013, the global sea level rose by $0.19 \mathrm{~m}$ from 1901 to 2010 , with an average sea level rise rate of $1.7 \mathrm{~mm} / \mathrm{a}$. From 1971 to 2010 , the average sea level rise rate reached 2.0mm/a. From 1993 to 2010, it reached 3.2mm /a (IPCC, 2013). The rate of sea level rise is accelerating. Bohai sea is the inland sea in China, surrounded by China's largest industrial concentration area, port area, and it is the third "growth pole" of China's economy. Also, it is one of the key areas where land subsidence, sea level rise, and other natural disasters are strictly. It is of great significance to study the change of sea level in the Bohai Sea for regional economic development, disaster prevention and reduction around the Bohai Sea.

The tide gauge station data and satellite altimetry data are the main data of the current sea level rise study. The tide gauge data has the characteristics of high precision and long duration, which is the main data for the study of medium and long-term sea level change (Douglas, 2001; Church et al., 2004; Chen et al., 2008). However, the sea level changes observed by tide gauges include the influence of vertical land motion (Vertical land motion contains long-time-scale vertical crustal motion and local land deformation, Haojian Feng et al., 1999). Previous studies have shown that the vertical land motion rate at tide gauges is the same as the sea level change rate (Teferle et al., 2006; Mazotti et al., 2008; Buble et al., 2010). It will have a great impact on the monitoring and research of sea level change. In order to study the inter-decadal and inter-centennial mechanisms of sea level change, the effects of vertical land motion must be determined and separated (Merrifield et al., 2009).

Using GNSS continuous observation technology to separate the influence of vertical ground motion of tide gauge station on sea level change analysis is a technical means of current coastal sea level rise research (Wöppelmann et al., 2007; Merrifield et al., 2009, Tingqin Du, 2009; Blewitt et al., 2010; Dongxu Zhou et al., 2016). Based on the long-term observation data of the co-located GNSS stations along the Bohai Sea coast, the vertical land motion of tide gauges in this region is calculated and analyzed. Also, Combined with the tide gauge data and satellite altimetry data, the preliminary research on the absolute sea level change in the Bohai Sea and the adjacent waters was carried out, so as to provide data reference for the verification of tidal benchmark and marine disaster prevention and reduction design around the Bohai Sea.

\section{DATA AND METHOD}

56 GNSS stations were constructed near the long-term tide gauge in China coastal by State Oceanic Administration People's Republic of China (SOA) at 2009, and service for monitoring and forecasting of sea level rise, oceanic meteorological. In this paper, the observation data of 9 GNSS stations around the Bohai Sea (the location distribution is shown in Fig. 1) are selected for analysis. The farthest distance between GNSS station and its adjacent tide gauge is $5.92 \mathrm{~km}$, within which the two stations can be considered to have the same vertical land motion (Collilieux and Wöppelmann, 2011, Stylianos et al., 2017). The sampling interval of GNSS observation data is 30 seconds and the data length is 5-9 years (as shown in Tab. 1).

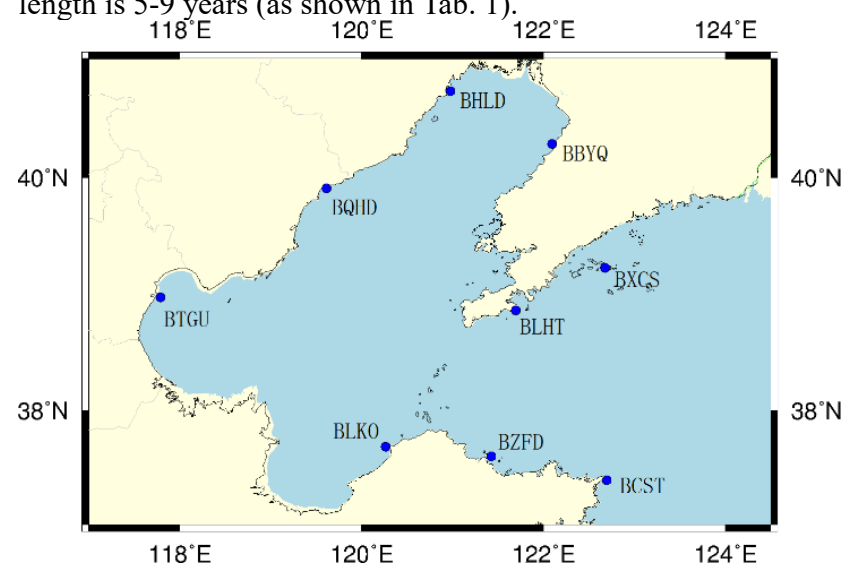

Figure 1. The co-located stations of GNSS and tide gauges 


\begin{tabular}{cccccc}
\hline GNSS & $\begin{array}{c}\text { Span and } \\
\text { range (unit: } \\
\text { year) }\end{array}$ & Latitude & longitude & $\begin{array}{c}\text { Distance } \\
\text { to co- } \\
\text { located } \\
\text { Tide } \\
\text { Gauges } \\
\text { (unit: } \\
\text { km) }\end{array}$ \\
\hline BXCS & $\begin{array}{c}2009.12- \\
2017.12\end{array}$ & 9 & $122^{\circ} 40^{\prime}$ & $39^{\circ} 13^{\prime}$ & 0.35 \\
BLHT & $\begin{array}{c}2009.8- \\
2017.12\end{array}$ & 9 & $121^{\circ} 41^{\prime}$ & $38^{\circ} 51^{\prime}$ & 1.43 \\
BBYQ & $\begin{array}{c}2009.12- \\
2017.12\end{array}$ & 9 & $122^{\circ} 05^{\prime}$ & $40^{\circ} 17^{\prime}$ & 0.00 \\
BHLD & $\begin{array}{c}2009.8- \\
2017.12\end{array}$ & 9 & $120^{\circ} 58^{\prime}$ & $40^{\circ} 43^{\prime}$ & 2.05 \\
BQHD & $\begin{array}{c}2013.2- \\
2017.12\end{array}$ & 5 & $119^{\circ} 36^{\prime}$ & $39^{\circ} 54^{\prime}$ & 1.08 \\
BTGU & $\begin{array}{c}2009.4- \\
2017.12\end{array}$ & 9 & $117^{\circ} 37^{\prime}$ & $38^{\circ} 58^{\prime}$ & 0.00 \\
BLKO & $\begin{array}{c}2013.4- \\
2017.12\end{array}$ & 5 & $120^{\circ} 15^{\prime}$ & $37^{\circ} 41^{\prime}$ & 5.92 \\
BZFD & $\begin{array}{c}2009.5- \\
2017.12\end{array}$ & 9 & $121^{\circ} 25^{\prime}$ & $37^{\circ} 35^{\prime}$ & 5.62 \\
BCST & $\begin{array}{c}2010.1- \\
2017.12\end{array}$ & 8 & $122^{\circ} 42^{\prime}$ & $37^{\circ} 23^{\prime}$ & 0.09 \\
\hline
\end{tabular}

Table 1. Statistics of GNSS data

NOTE: Distance $=0.00$ means the GNSS observation pier built on the roof of tide station.

The processing of the daily 30-second GNSS data was carried out by using the Bernese GPS software (rel. 5.2), and data time span varies from 4 to 9 years. In our GNSS process strategy, models for solid Earth tides (IERS2010), pole tides (IERS2000), ocean loading (FES2014), earth rotation (IERS C04) were applied in order to remove the effect in station coordinates due to the geopotential field. The GMF mapping function was applicated to estimate the tropospheric delay. The absolute antenna center correction model for satellites and receivers was used in the processing to reduce systematic effects in the height component. The coordinate available in reference frame of ITRF2005 was turned to ITRF 2008 through Helmert transformation in order to analysis the vertical velocity at the same frame. Finally, the station coordinates were transformed from Geocentric coordinate system $(\mathrm{X}, \mathrm{Y}, \mathrm{Z})$ to topocentric coordinate system $(\mathrm{N}, \mathrm{E}, \mathrm{U})$ by the equation (1), where $\theta, \varphi$ is the latitude and longitude of each site, respectively (e.g. Fotiou and Pikridas 2012).

$$
\left[\begin{array}{l}
N \\
E \\
U
\end{array}\right]_{i}=\left[\begin{array}{ccc}
-\sin \theta \cos \varphi & -\sin \theta \sin \varphi & \cos \theta \\
-\sin \varphi & \cos \varphi & 0 \\
\cos \theta \cos \varphi & \cos \theta \sin \varphi & \sin \theta
\end{array}\right] \times\left[\begin{array}{l}
X \\
Y \\
Z
\end{array}\right]_{i}
$$

\section{ANALYSIS OF VERTICAL LAND MOTION AT TIDE GAUGES}

\subsection{Periodic Analysis of Elevation Time Series}

The existing research results show that the GNSS elevation time series has a certain periodicity. In this paper, the periodogram method (lomb algorithm) is used to analyze the spectrum of GPS elevation time series of tidal stations, and the main period is determined by the $\mathrm{F}$ test of variance $(\mathrm{a}=0.05)$. The Lomb algorithm can directly perform spectral analysis on nonequidistant sampling data. The algorithm formula is as follows:

$$
S(\omega)=\frac{1}{2 \sigma^{2}}\left\{\frac{\left[\sum_{i=1}^{N}\left(\mathrm{x}_{i}-\overline{\mathrm{x}}\right) \cos \omega\left(\mathrm{t}_{i}-\tau\right)\right]^{2}}{\sum_{i=1}^{N} \cos ^{2} \omega\left(\mathrm{t}_{i}-\tau\right)}+\frac{\left[\sum_{i=1}^{N}\left(\mathrm{x}_{i}-\overline{\mathrm{x}}\right) \sin \omega\left(\mathrm{t}_{i}-\tau\right)\right]^{2}}{\sum_{i=1}^{N} \sin ^{2} \omega\left(\mathrm{t}_{i}-\tau\right)}\right\}
$$

Where $\omega=$ Laplace change frequency response value

$\sigma=$ sampling error

$\overline{\mathrm{X}}=$ sampling average

$\tau=$ Phase shift factor and is given by

$$
\tan (2 \omega \tau)=\frac{\sum_{i=1}^{N} \sin \left(2 \omega \mathrm{t}_{i}\right)}{\sum_{i=1}^{N} \cos \left(2 \omega \mathrm{t}_{i}\right)}
$$

The results periodic analysis of elevation time series of each GNSS station are shown in Table 2, mainly including annual, semi-annual and seasonal variation periods.

\begin{tabular}{cl|cl}
\hline $\begin{array}{c}\text { GPS } \\
\text { stations }\end{array}$ & $\begin{array}{c}\text { Significant } \\
\text { Periodic }\end{array}$ & $\begin{array}{c}\text { GPS } \\
\text { stations }\end{array}$ & \multicolumn{1}{c}{$\begin{array}{c}\text { Significant } \\
\text { Periodic }\end{array}$} \\
\hline BXCS & $0.4,1,2$ & BTGU & $0.34 、 1 、 2$ \\
BLHT & $0.4,0.5,2$ & BLKO & $0.5,1$ \\
& $0.3 、 0.726 、$ & BZFD & $0.705 、 1 、 2$ \\
BBYQ & 1.02 & & $0.33 、 0.715 、 1 、$ \\
BHLD & $0.4 、 0.715 、 1 、$ & BCST & 2 \\
& 2 & & \\
BQHD & $0.31 、 0.5 、$ & & \\
\hline
\end{tabular}

Table 2. Result of Significant Periodic Inspection $\left(\boldsymbol{F}_{\boldsymbol{\alpha}}=\mathbf{2 . 9 9}\right)$

\subsection{Trend Analysis of Vertical Ground Motion of Tide Gauge}

The time series of GNSS elevation is mainly composed of initial elevation term, linear variation term and periodic variation term (Wenhai Jiao. 2004), which can be expressed by trigonometric polynomial function as follows:

$\delta(t)=\delta\left(t_{0}\right)+\Delta \delta\left(t-t_{0}\right)+\sum_{i=1}^{n}\left[a_{i} \cos \left(\frac{2 \pi}{T_{i}}\left(t-t_{0}\right)\right)-b_{i} \sin \left(\frac{2 \pi}{T_{i}}\left(t-t_{0}\right)\right)\right]$

Where $\delta(t)=$ the elevation in time $\mathrm{t}$

$\delta\left(t_{0}\right)=$ the mean elevation relative to $t_{0}$

$\Delta \delta=$ the linear rate of elevation change, and the unit is $\mathrm{mm} / \mathrm{yr}$

$\sum_{i=1}^{n}\left[a_{i} \cos \left(\frac{2 \pi}{T_{i}}\left(t-t_{0}\right)\right)-b_{i} \sin \left(\frac{2 \pi}{T_{i}}\left(t-t_{0}\right)\right)\right]=$ the periodic variation item

$n=$ the number of periodic items

$T_{i}=$ the main period value

$a_{i}, b_{i}=$ the coefficients to be solved

According to the periodic analysis results in Section 3.1, the ground vertical motion of each tide gauge is analyzed by Equation 3 and least squares estimation. The trend and rate of the vertical motion are shown in Fig. 2 and Fig. 3. 

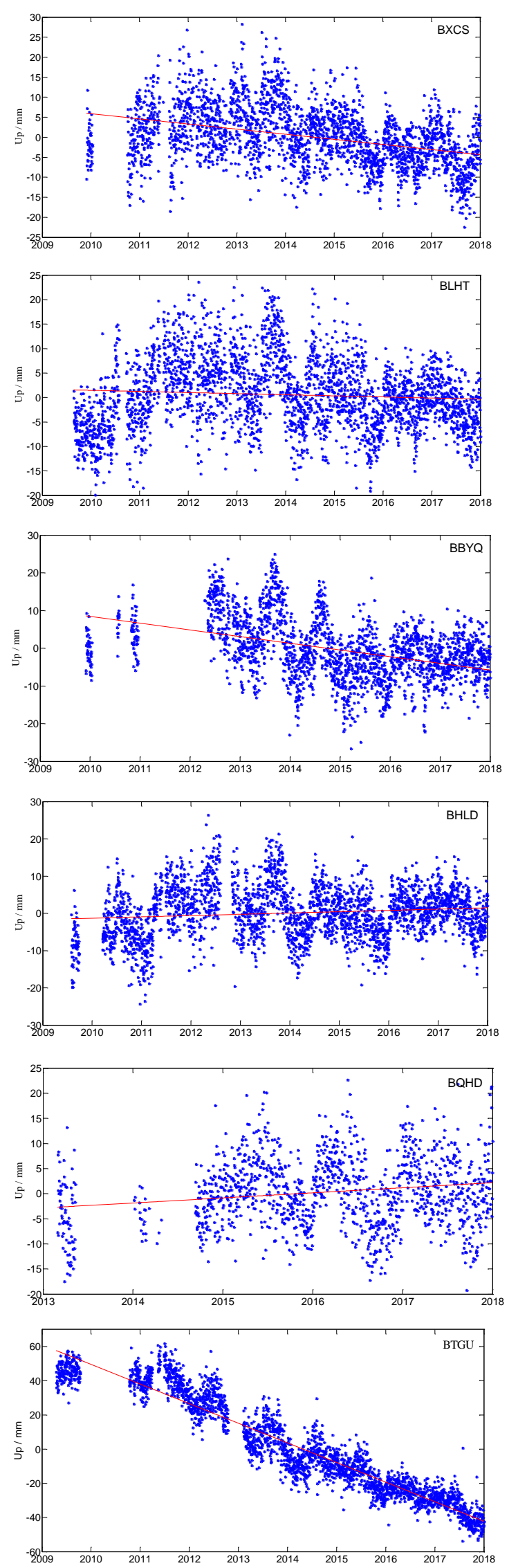
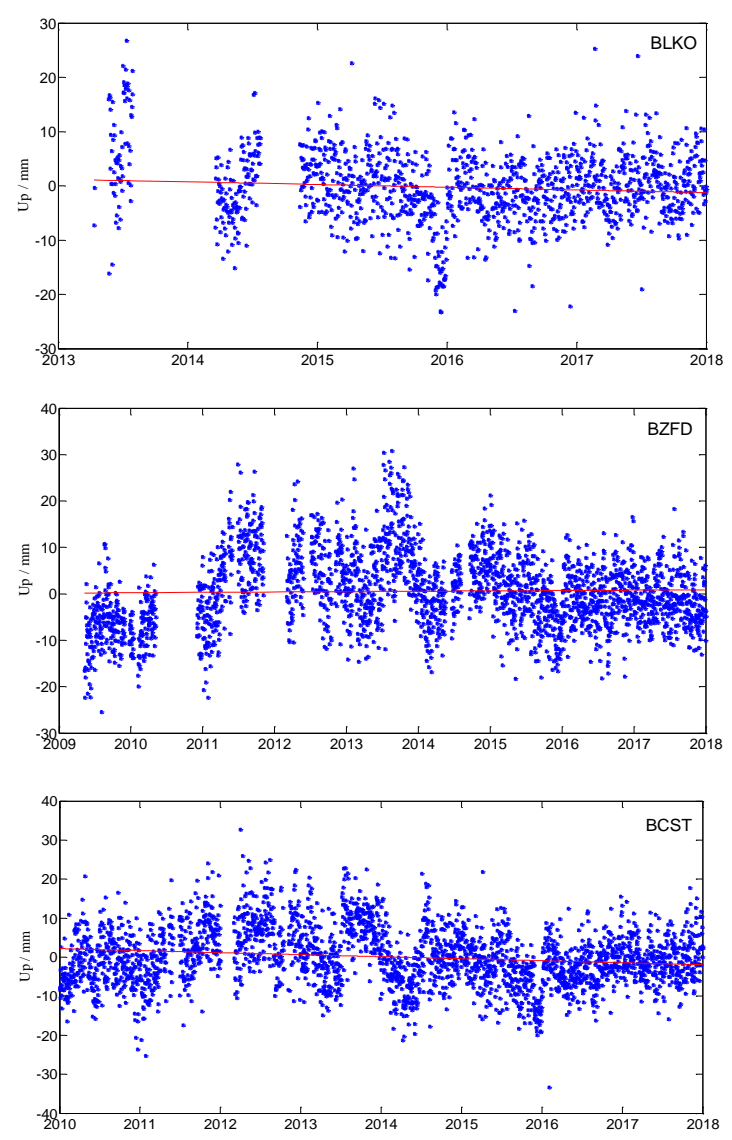

Figure 2. Daily vertical position time-series from GNSS

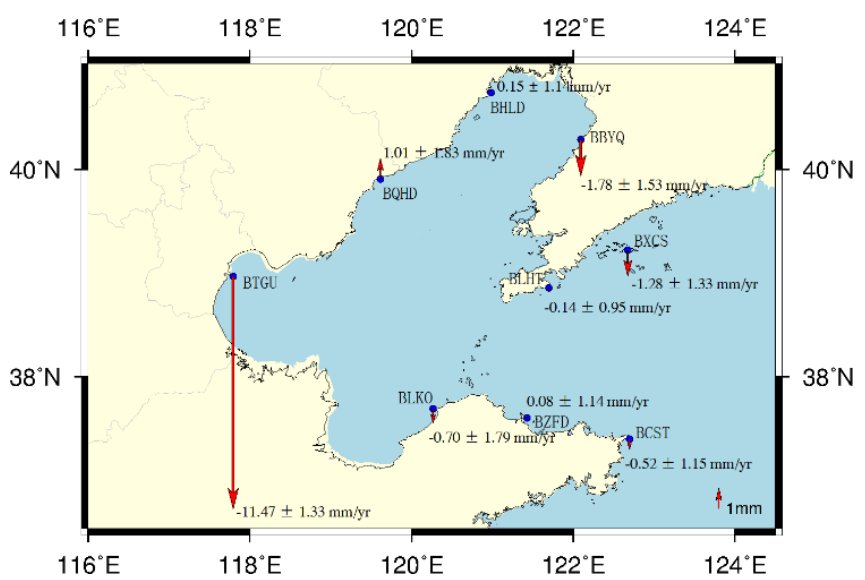

Figure 3. Vertical velocities in co-located sites in Bohai sea The crustal deformation of the tide gauge station in the east of the Bohai Sea is dominated by a downward trend. Among them, the land subsidence trend in the BBYQ and BXCS was significant, with an average annual settlement of more than $1 \mathrm{~mm}$. The land subsidence trend in the BLHT tide gauge is gentle, and the annual average settlement is about $0.14 \mathrm{~mm}$. The vertical land motion of tide gauges in this area has a gradually decreased trend from north to south.

The vertical land motion of BHLD Station is slowly increasing, with an average annual rising rate of $0.15 \mathrm{~mm} / \mathrm{yr}$. The BQHD shows an upward trend of about $1.01 \mathrm{~mm} / \mathrm{yr}$, which corresponds to the location of the Yanshan tectonic belt and Shanhaiguan uplift area.

BTGU Station has a settlement trend of $11.47 \mathrm{~mm} / \mathrm{yr}$, which is located in the subsidence zone of North China and built in the Tianjin wharf. Field investigation and analysis suggest that the settlement rate of the station may be affected by the land 
subsidence in Tianjin area and the wharf's own subsidence. On the southeastern side of Bohai Sea, the BLKO Station shows a slow downward trend, with an annual change rate of $0.7 \mathrm{~mm} / \mathrm{yr}$. The trend of BZFD Station was stable, with an annual increase rate of $0.08 \mathrm{~mm} / \mathrm{yr}$. The BCST Station shows a downward trend of $0.52 \mathrm{~mm} / \mathrm{yr}$.

\section{TRENDS OF ABSOLUTE SEA LEVELS}

Without considering the influence of environmental factors such as local sea surface pressure field and Marine dynamic field variation (Juncheng Zuo, et al., 1994, Changlin Chen, et al., 2012), the more real sea level change can be obtained by separating the vertical land motion in the sea level change observed by the tide gauge, which is called the absolute sea level change. The relationship can be described as follows

$$
\Delta \delta^{\prime}=\Delta H_{0}+\Delta \delta
$$

Where $\quad \Delta \delta^{\prime}=$ the change rate of absolute sea level

$$
\begin{aligned}
& \Delta H_{0}=\text { the deformation rate of vertical crustal } \\
& \Delta \delta=\text { the change rate of relative sea level. }
\end{aligned}
$$

$\Delta H_{0}$ and $\Delta \delta$ are two independent observations. So, the uncertainties of $\Delta \delta^{\prime}$ can be expressed as $\sigma=\sqrt{\sigma_{H}^{2}+\sigma_{\delta}^{2}}$, where, $\sigma_{H}$ and $\sigma_{\delta}$ are the uncertainties of the $\Delta H_{0}$ and the $\Delta \delta$, respectively.

The absolute sea level trend uncertainties re-estimated as described in Table 3 following the formula $\sigma=\sqrt{\sigma_{H}^{2}+\sigma_{\delta}^{2}}$, considering that the two different techniques are uncorrelated. Relative sea level changes of nine tide gauges in Bohai Sea from 1993 to 2012 published by Liu Shouhua et al. (2015) in Chinese scientific journals are quoted directly. The analysis of relative sea level change rate is no longer carried out here.

At the same time, the monthly mean sea level anomalous high grid value provided by AVISO during 1993-2012 are used to extract the absolute sea level rise rate at nine stations and the absolute sea level rise in the Bohai Sea and its surrounding sea areas. In the selection and processing of satellite altimetry data grid products, the selection of monthly mean sea level anomalous high grid points is designed based on the characteristics of shoreline distribution at tide stations and the effective monitoring distance of tide level at tide stations. The effective grid data in the sea area between $40 \mathrm{~km}$ parallel coastline at a midpoint and $20-60 \mathrm{~km}$ offshore are selected to determine the absolute sea level change at the tide gauge station using the method of inverse distance weighting in order to weaken the influence of poor quality of near-shore satellite altimetry data.

\begin{tabular}{ccccc}
\hline & & Relative & \multicolumn{2}{c}{ Absolute sea level } \\
\cline { 4 - 5 } Sites & Vertical & sea level & & \\
& velocities & Tide & & \\
& GNSS & gauge & GNSS+TG & Altimetry \\
& & $(\mathrm{TG})$ & & \\
\hline \multirow{2}{*}{ BXCS } & $-1.28 \pm$ & $3.3 \pm 1.7$ & $2.02 \pm$ & $3.52 \pm$ \\
& 1.33 & & 2.16 & 2.04 \\
BLHT & $-0.14 \pm$ & $4.0 \pm 1.4$ & $3.86 \pm$ & $3.90 \pm$ \\
& 0.95 & & 1.69 & 1.87 \\
BBYQ & $-1.78 \pm$ & $0.0 \pm 2.5$ & $-1.78 \pm$ & $3.19 \pm$ \\
& 1.53 & & 2.93 & 2.28 \\
BHLD & $0.15 \pm$ & $3.6 \pm 2.1$ & $3.75 \pm$ & $3.16 \pm$ \\
& 1.14 & & 2.39 & 2.32 \\
BQHD & $1.01 \pm$ & $2.3 \pm 1.4$ & $3.31 \pm$ & $3.18 \pm$ \\
& 1.83 & & 2.30 & 2.14 \\
\hline
\end{tabular}

\begin{tabular}{ccccc}
\hline \multirow{2}{*}{ BTGU } & $-11.47 \pm$ & $5.3 \pm 2.4$ & $-6.17 \pm$ & $3.04 \pm$ \\
& 1.33 & & 2.73 & 2.66 \\
BLKO & $-0.70 \pm$ & $5.7 \pm 1.6$ & $5.00 \pm$ & $3.66 \pm$ \\
& 1.79 & & 2.40 & 2.25 \\
BZFD & $0.08 \pm$ & $3.5 \pm 1.5$ & $3.58 \pm$ & $3.88 \pm$ \\
& 1.14 & & 1.88 & 1.94 \\
BCST & $-0.52 \pm$ & $4.3 \pm 1.6$ & $3.78 \pm$ & $3.89 \pm$ \\
& 1.15 & & 1.97 & 1.76 \\
\hline
\end{tabular}

Table 3. Absolute sea level at nine sites (Unit: $\mathrm{mm} / \mathrm{yr}$ ) *Note: The relative sea level change rate is quoted from the paper "Vertical motions of tide gauge stations near the Bohai Sea and Yellow Sea" (Shouhua Liu et al., 2015).

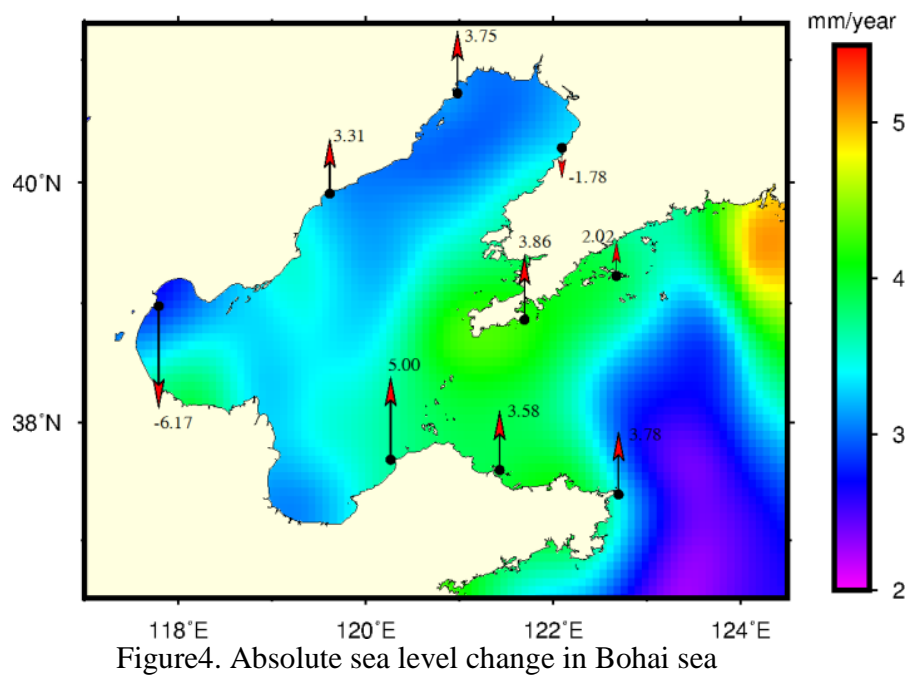

The red arrow means the absolute sea level from GNSS+TG,

Vectogram means of the absolute sea level from altimetry (1993-2012)

By analyzing the results in Table 3 and Figure 4, the absolute sea level changes of BTGU and BBYQ stations obtained from the combination of tide gauge and GNSS observation shows a declining trend. This is contrary to the inversion results from satellite altimetry data, and also contradicts the overall rising trend of sea level along the coast of China. The results of these two stations are not adopted in the subsequent analysis of sea level changes.

The other seven stations were used to analyze sea level changes in the Bohai Sea and surrounding waters. During the period 19922012, the absolute sea level in the Bohai Sea and its surrounding waters increased at an average rate of $3.61 \mathrm{~mm} / \mathrm{yr}$ (GNSS+TG). It is in good agreement with the inversion results of satellite altimetry $(3.60 \mathrm{~mm} / \mathrm{yr})$. The average rate of relative sea level rise is $3.81 \mathrm{~mm} / \mathrm{yr}$, both absolute and relative sea level changes are higher than the global average rate in the same period $(3.2 \mathrm{~mm}$ $/ \mathrm{yr})$. The overall correction of land vertical motion of the seven tide gauges is $-0.21 \mathrm{~mm} / \mathrm{yr}$.

It can be estimated from the two stations of BHLD and BQHD, the absolute sea level rise rate and the relative sea level rise rate is about $3.53 \mathrm{~mm} / \mathrm{yr}$ and $2.95 \mathrm{~mm} / \mathrm{yr}$ on the northwestern part of the Bohai Sea, respectively. From the five stations of BLKO, BZFD, BLHT, BCST and BXCS, it is inferred that the absolute sea level rise rate around the boundary of bohai sea and yellow sea is about $3.65 \mathrm{~mm} / \mathrm{yr}$ and the relative sea level rise rate is about $4.16 \mathrm{~mm} / \mathrm{yr}$. The difference of relative sea level rise between the two sea areas is about $1.21 \mathrm{~mm} / \mathrm{yr}$. After the correction of the vertical land motion of the tide gauge, the difference induces to $0.13 \mathrm{~mm} / \mathrm{yr}$, which indicates that the vertical land motion of the tide gauge is the main reason for the regional difference of relative sea level change. 


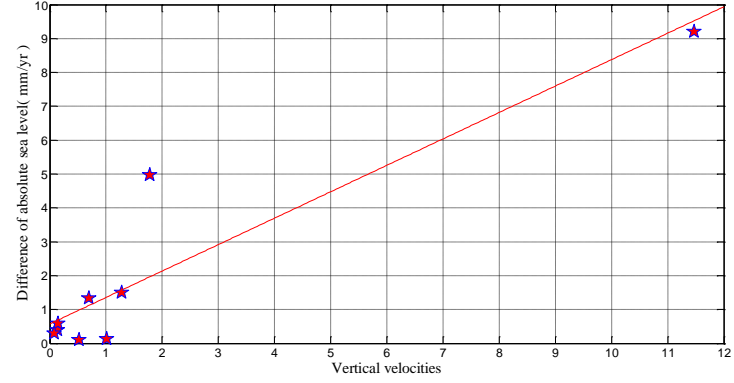

Figure 5. The connection between vertical velocities and the difference of the absolute sea level from GNSS+TG and Altimetry

By comparing the absolute sea level rise rate at the 9 tide gauges obtained by GNSS+TG and Altimetry in Table 3, the difference in the rate of rise of the BTGU station is the largest, reaching $9.21 \mathrm{~mm} / \mathrm{yr}$. The difference of the rising rate of BBYQ station is $4.97 \mathrm{~mm} / \mathrm{yr}$, that of BXCS station is $1.50 \mathrm{~mm} / \mathrm{yr}$, that of BLKO station is $1.34 \mathrm{~mm} / \mathrm{yr}$, and that of the other five stations is less than $0.6 \mathrm{~mm} / \mathrm{yr}$. Comparing the absolute sea level rise rates of the nine tide gauges with the absolute vertical land motion rates of each station, it is found that there is a significant positive correlation between them (as shown in Fig. 5). That is, the greater the absolute value of the vertical land motion rate of the tide station, the greater the difference in the absolute sea level rise rate obtained by the two methods, and the correlation coefficient is 0.78 .

The distance between the tidal station and the benchmarking point in China is generally less than a few kilometers. The joint leveling between the two cannot effectively correct the vertical land motion in the area of tens or even hundreds of kilometers. Moreover, large-scale leveling is costly, time-consuming and difficult to be carried out in high frequency (Shouhua Liu, 2015). Whether the occurance of the above positive characteristics and the negative values of the absolute sea level change rate at BTGU and BBYQ gauges are related to the failure revised of the vertical land motion of the tide gauge during the verification of the tidal level benchmark need further analysis and research.

\section{DISCUSSION}

In this paper, the vertical land motion of 9 tide gauges around the Bohai Sea is analyzed by using the continuous observation data of co-located GNSS stations in the past nine years. Also, combined with tide gauges data and satellite altimetry data, the absolute sea level changes from 1993 to 2012 are analyzed.

GNSS monitoring results show that the vertical land motion of BXCS, BLHT, BBYQ, BTGU, BLKO, BCST and other tide stations shows a subsidence trend, and the subsidence rate is between $0.14-11.47 \mathrm{~mm} / \mathrm{yr}$. The vertical land motion of tide gauges such as BHLD, BQHD and BZFD shows a uplift trend, and the rising rate is between $0.08-1.01 \mathrm{~mm} / \mathrm{yr}$. Among them, the vertical land motion rates of BXCS, BBYQ, BTGU and BQHD stations are all greater than $1 \mathrm{~mm} / \mathrm{yr}$, which are in the same order of magnitude as sea level rise rates. Therefore, special attention should be paid to the influence of vertical land motion on sea level change analysis.

The relative sea level rise rate of the Bohai sea and its adjacent waters is about $3.81 \mathrm{~mm} / \mathrm{yr}$. After the influence of the vertical land motion of the tide gauges is separated, the absolute mean sea level rise rate is $3.61 \mathrm{~mm} / \mathrm{yr}$, and the sea level rise rate in this sea area is slightly higher than the global average change rate. At the same time, it is found that the vertical land motion is the main reason for the regional difference of relative sea level change. The preliminary analysis results show that GNSS observation technology can play an important role in the monitoring of vertical land motion at tide gauges and the studying of the sea level change.

\section{Acknowledgements}

The authors would like to thank LIU Shouhua for the results of relative sea level rise, the AVISO for providing the gridded satellite altimetry data, the GNSS Center in The First Institute of Oceanography, Ministry of Natural Resources for providing the GNSS data.

This work was supported by the Natural Science Foundation of China (Grant No.41706115, 41876111, 40706038, 41806214), the National Key R\&D Program of China (2016YFB0501703, 2017YFC0306003, 2018YFC0309901).

We thank the anonymous reviewers for their constructive comments and editorial suggestions that have significantly improved the quality of the paper.

\section{REFERENCES}

Blewitt G, Altamini Z, Davis J, Gross R, Kuo C Y, Lemoine F, Neilan R, Plag H P, Rothacher M, Shum C K, Sideris M G, Schone T, Tregoning P, Zerbini S. 2010. Geodetic observations and global reference frame contributions to understanding sea level rise and variability. In: Church J, Woodworth P, Aarup T, eds. Understanding Sea Level Rise and Variability. Chichester: Wiley-Blackwell. 256-284

Buble G, Bennett R A, Hreinsdottir S. 2010. Tide gauge and GPS measurements of crustal motion and sea level rise along the eastern margin of Adria. J Geophy Res, 115: B02404, doi: 10.1029/2008JB006155

Cazenave A, Dominh K, Ponchaut F, Soudarin L, Cretaux J F, Le Provost C. 1999. Sea level changes from TOPEXPOSEIDON altimetry and tide gauges, and vertical crustal motions from DORIS. Geophy Res Lett, 26: 2077-2080

Chen M., Zuo J., Chen M., Zhang J., Du L. 2008. Spatial distribution of sea level trend and annual range in the China Seas from 50 long term tidal gauge station data. In: Jin S C, Seok W H, Prinsenberg S, eds. ISOPE Symposium. Vancouver. 583-587

Church J A, White N J, Coleman R, Lambeck K, Mitrovica J X. 2004. Estimates of the regional distribution of sea level rise over the 1950 to 2000 period. J Clim, 17: 2609-2625

Collilieux, X., and G. Wöppelmann. 2011. Global sea-level rise and its relation to the terrestrial reference frame. Journal of Geodesy 85(1): 9-22. doi:10.1007/s00190-010-0412-4

Douglas B C. 2001. Sea level change in the era of the recording tide gauge. In: Douglas B C, Kearney M S, Leatherman S P, eds. Sea Level Rise: History and Consequences. California: Academic Press. 37-64

Fotiou, A., and Pikridas, C. 2012. GPS and Geodetic Applications. Thessaloniki: Ziti publications. ISBN:978-960456-346-3

Han Y., Chen F., Yang G., Liu X.. Characteristics of Presentday Crust Vertical Deformation and Earthquake Risk Analyzes in Northern Area of North China[J]. Journal of Geodesy and Geodynamics. 2010, 30(2):25-28 
Hu H., Huang L., Yang G.. Recent vertical crustal deformation in the coastal area of eastern China[J]. Scientia Geologica Sinica, 1993, 28(3):270 278

IPCC. 2013. Climate Change 2013: The Physical Science Basis. Contribution of Working Group I to the Fifth Assessment Report. Final Draft Underlying Scientific-Technical Assessment (7 June 2013). Technical Summary Ts-12

Jiao W., Wei Z., Guo H. et al. Determination of the Absolute Rate of Sea Level by Using GPS Reference Station and Tide Gauge Data [J]. Geomatics and Information Science of Wuhan University, 2004,29(10):901-904

Liu J., Yao Y., Shi C., et al. Preliminary research on characteristic of present-day vertical deformation of China mainland $[\mathrm{J}]$. Journal Of Geodesy And Geodynamics, 2002,22(3):1 5

Liu S., Chen C., Liu K., Mu L, Wang H, Wu X., Zhang J., Duan X., Gao J. 2015. Vertical motions of tide gauge stations near the Bohai Sea and Yellow Sea. Science China: Earth Sciences, doi: 10.1007/s11430-015-5167-6

Mazzotti S, Jones C, Thomson R E. 2008. Relative and absolute sea level rise in western Canada and northwestern United States from a combined tide gauge-GPS analysis. J Geophy Res, 113: C11019, doi: 10.1029/2008JC004835

Merrifield M, Aarup T, Allen A, Aman A, Caldwell P, Bradshaw E, Zavala J. 2009. The global sea level observing system (GLOSS). Proceedings of Ocean Obs, 9

Bitharis S, Ampatzidis D, Pikridas C, et al. The Role of GNSS
Vertical Velocities to Correct Estimates of Sea Level Rise from Tide Gauge Measurements in Greece[J]. Marine Geodesy, 2017(5)

State Oceanic Administration People's Republic of China. Bulletin of the Chinese sea level [EB/OL]. http://www.coi.gov.cn/ gongbao/haipingmian.

Teferle F N, Bingley R M, Williams S D P, Baker T F, Dodson A H. 2006. Using continuous GPS and absolute gravity to separate vertical land movements and changes in sea-level at tide-gauges in the UK. Philos Trans R Soc A-Math Phys Eng Sci, 364: 917-930

Wöppelmann G, Martin M B, Bouin M N, Altamimi Z. 2007. Geocentric sea-level trend estimates from GPS analyses at relevant tide gauges world-wide. Glob Planet Change, 57: 396406

Wöppelmann G, Marcos M. 2012. Coastal sea level rise in southern Europe and the nonclimate contribution of vertical land motion. J Geophy Res, 117: C01007

Ying S., Zhang Z., Geng S., et al. Basic characteristics of recent vertical crustal movement of China mainland [J]. Earthquake Research In China, 1988, 4(4):1 8.

Zhou D., Zhou X., Zhang H., Wang Z., Tang Q.. Analysis of the Vertical Deformation of China Coastal Tide Stations Based on GPS Continuous Observations [J]. Geomatics and Information Science of Wuhan University, 2016, 41(4):516-522 